\title{
DUE-DATE ASSIGNMENT AND OPTIONAL MAINTENANCE ACTIVITY SCHEDULING PROBLEM WITH LINEAR DETERIORETING JOBS
}

\author{
Chou-Jung Hsu \\ Department of Industrial Engineering and Management, Nan Kai University of Technology, Nan-Tou, Taiwan 542, \\ R.O.C.
}

Suh-Jenq Yang

Department of Industrial Engineering and Management, Nan Kai University of Technology, Nan-Tou, Taiwan 542,

R.O.C.

Dar-Li Yang

Department of Information Management, National Formosa University, Yun-Lin, Taiwan 632, R.O.C., dlyang@nfu.edu.tw

Follow this and additional works at: https://jmstt.ntou.edu.tw/journal

Part of the Computer Sciences Commons, and the Engineering Commons

\section{Recommended Citation}

Hsu, Chou-Jung; Yang, Suh-Jenq; and Yang, Dar-Li (2011) "DUE-DATE ASSIGNMENT AND OPTIONAL MAINTENANCE ACTIVITY SCHEDULING PROBLEM WITH LINEAR DETERIORETING JOBS," Journal of Marine Science and Technology. Vol. 19: Iss. 1, Article 11.

DOI: $10.51400 / 2709-6998.2141$

Available at: https://jmstt.ntou.edu.tw/journal/vol19/iss1/11

This Research Article is brought to you for free and open access by Journal of Marine Science and Technology. It has been accepted for inclusion in Journal of Marine Science and Technology by an authorized editor of Journal of Marine Science and Technology. 


\title{
DUE-DATE ASSIGNMENT AND OPTIONAL MAINTENANCE ACTIVITY SCHEDULING PROBLEM WITH LINEAR DETERIORETING JOBS
}

\author{
Chou-Jung Hsu*, Suh-Jenq Yang*, and Dar-Li Yang**
}

Key words: scheduling, linear deterioration, due-data assignment, maintenance activity, earliness, tardiness.

\begin{abstract}
The focus of this work is to analyze linear deteriorating jobs in a single-machine scheduling problem with due-date assignment and maintenance activity. The linear deteriorating jobs means its processing time is an increasing function of their starting time. The objective is to minimize the total of earliness, tardiness and due-date cost. To solve the scheduling problem addressed in this work, we have to determine the job sequence, the common due-date, and the location of a maintenance activity. We show that the problem can be solved optimally in $O\left(n^{2} \log n\right)$ time.
\end{abstract}

\section{INTRODUCTION}

The deterioration job scheduling problem was introduced by Browne and Yechiali [3]. They considered $n$ jobs, all available for processing at time 0 , with initial processing requirements $a_{i}$. If job $i$ 's processing is delayed until $t$, they assumed that the initial requirement deteriorates in such a manner that its processing requirement grows linearly with the delay to $P_{i}(t)=a_{i}+b_{i} t$, where $b_{i}$ is job $i$ 's processing growth rate, $a_{i}$ is the basic processing time for job $i$ and $t$ is the time at which processing of job $i$ begins. Kunnathur and Gupta [11] and Mosheiov [14] pointed out several real-life situations in which deteriorating jobs might occur. These include shops with deteriorating machines, and/or delay of maintenance or cleaning, fire fighting, hospital emergency wards and steel rolling mills. Such problems also occur when the machine, not the job, is deteriorating, so that jobs processed later require a

Paper Submitted 10/01/09; revised 01/14/10; accepted 01/22/10. Author for correspondence: Dar-Li Yang (e-mail: dlyang@nfu.edu.tw).

*Department of Industrial Engineering and Management, Nan Kai University of Technology, Nan-Tou, Taiwan 542, R.O.C.

**Department of Information Management, National Formosa University, Yun-Lin, Taiwan 632, R.O.C. longer processing time. Mosheiov [15] further considered another linear deterioration model $\left(p_{i}=a_{i}+b t_{i}\right)$ and showed that the problem to minimize the total weighted completion time is also polynomially solvable. Machine scheduling problems with deteriorating jobs and/or learning effects have been extensively studied in the last two decades in various machine settings and performance measures. For a complete list of studies, the readers may refer to the comprehensive survey by Alidaee and Womer [1] and Cheng et al. [5].

The problems with due date determination have received considerable attention in the last two decades due to the introduction of new methods of inventory management such as just-in-time concepts. In just-in-time systems, jobs are to be completed neither too early nor too late, otherwise, they lead to the scheduling problems with both earliness and tardiness costs and assigning due dates. Cheng et al. [6] studied a single-machine due-date assignment scheduling problem with the deterioration model $\left(p_{i}=a_{i}+b t_{i}\right)$ where $t_{1}=0$. The objective is to minimize the total of the due-date, earliness and tardiness penalties. They provided some properties and an algorithm to solve the problem in $O(n \log n)$. Kuo and Yang [12] gave a concise analysis of the problem introduced by Cheng et al. [6] and provided a simpler algorithm for the problem. Chang et al. [4] considered the due-date assignment and single-machine scheduling with a learning/aging effect. The objective is to determine the optimal common due date and the optimal sequence of jobs that minimizes a cost function in the presence of learning/aging effect. The authors provided polynomial algorithms to solve the problem under different learning/ aging index assumptions. For a complete list of studies, the readers may refer to the comprehensive survey by Baker and Scudder [2] and Gordon et al. [7].

Production scheduling and preventive maintenance planning are the most common and significant problems faced by the manufacturing industry. During the maintenance activity, the machine is unavailable for processing jobs. This imposes a constraint on the machine availability for production. Lately plentiful research has been conducted to address the maintenance activity in scheduling under different machine environments. For details on this stream of research, the readers 
may refer to the comprehensive surveys by Wang [18] and Ma et al. [13]. To the best of our knowledge, Mosheiov and Oron [16] is the first that studied maintenance activity scheduling and due-date assignment simultaneously. The objective is to minimize the total of earliness, tardiness and due-date cost. They provided a polynomial time algorithm to solve the problem for any $\delta_{j}>0$. Gordon and Tarasevich [8] also studied the same problem proposed by Mosheiov and Oron [16]; for the case of $0<\delta_{j}<1$, they described some properties to reduce the runtime of the algorithm for solving the problem.

Motivated by some practical manufacturing environments, such as cold drawing, cold pressing, cold forming, and cold extrusion in the metal forming process, we study a singlemachine due-date assignment problem with the option of scheduling a maintenance activity under linear deteriorating jobs. To model the problem more realistic, assume that once the maintenance activity has been completed, machine will revert to its initial condition. The objective is to minimize the total of earliness, tardiness and due-date cost. We introduce a polynomial solution for the problem.

\section{ASSUMPTIONS AND THE PROBLEM DESCRIPTION}

The following notations are used throughout the study:

$n:$ the total number of jobs to be processed;

$J_{i}:$ the job $i$;

$l$ : the length of a maintenance activity;

$d$ : the common due-date;

$a_{i}$ : the basic processing time of $J_{i}, i=1,2, \ldots, n$;

$P_{i}$ : the actual processing time for the job scheduled in the $i$ th position in a sequence, $i=1,2, \ldots, n$;

$C_{i}$ : the completion time for the job processed in the $i$ th position in a sequence, $i=1,2, \ldots, n$;

$E_{i}$ : the earliness of job scheduled in the $i$ th position in a sequence, $i=1,2, \ldots, n$, i.e. $E_{i}=\max \left\{0, d-C_{i}\right\}$;

$T_{i}$ : the tardiness of job scheduled in the $i$ th position in a sequence, $i=1,2, \ldots, n$, i.e. $T_{i}=\max \left\{C_{i}-d, 0\right\}$.

The problem under consideration can be formally described as follows: There are $n$ independent jobs $N=\left\{J_{1}, J_{2}, \ldots, J_{n}\right\}$ to be processed on a single-machine which is available at time 0 . The processing time $p_{i}$ of $J_{i}$ is given as a linear increasing function of its starting time $t$. That is, $p_{i}=a_{i}+b t$, where $b$ is a constant growth rate and $t$ is the time at which processing of job $i$ begins. All jobs are assumed to have a common due-date $d$. This due-date is a decision variable. Assume that once the maintenance activity has been completed, machine will revert to its initial condition. Therefore, if job $j$ is the first job scheduled after the maintenance activity, then its starting time is set to 0 , i.e. $t=0$. The maintenance activity is an option. Then, the problem under consideration is to find an optimal due-date $d$, an optimal position of the job before which the maintenance activity is scheduled, and an optimal schedule $\pi$ that mini- mizes the following function:

$$
Z=f(d, \pi)=\sum_{i}\left(\alpha E_{i}+\right) \beta T_{i}+\gamma d,
$$

where $\alpha>0, \beta>0$, and $\gamma>0$ are the unit earliness, tardiness and due-date penalties, respectively. Using the three-field notation of Graham et al. [9] the problem can be denoted as $1\left|a c, p_{i}=a_{i}+b t\right| \sum_{i}\left(\alpha E_{i}+\beta T_{i}+\gamma d\right)$, where $a c$ in the second field denotes an optional maintenance activity.

\section{AN OPTIMAL SOLUTION FOR PROBLEM}

$$
1\left|a c, p_{i}=a_{i}+b t\right| \sum_{i}\left(\alpha E_{i}+\beta T_{i}+\gamma d\right)
$$

Mosheiov and Oron [16] showed that several properties of an optimal solution for the original due-date assignment problem, provided by Panwalker et al. [17], continue to hold when a rate modifying activity is assumed. Taking advantages of the analysis in the Mosheiov and Oron [16], the following Property 1 also holds. Thus, we omit the proof.

Property 1. For the problem $1\left|a c, p_{i}=a_{i}+b t\right| \sum_{i}\left(\alpha E_{i}+\beta T_{i}+\right.$ $\gamma d)$, it is optimal to assign the due date at the completion time of the $k$ th job, where $k$ is the smallest integer greater than or equal to $(n \beta-n \gamma) /(\alpha+\beta)$.

Property 2 [10]. Let there be two sequences of numbers $x_{i}$ and $y_{i}$. The sum $\sum_{i} x_{i} y_{i}$ of products of the corresponding elements is the least (largest) if the sequences are monotonic in the opposite (same) sense.

For a specific schedule $\pi=\left(J_{1}, J_{2}, \ldots, J_{i}, a c, J_{i+1}, \ldots, J_{n}\right)$, then the actual processing time of jobs can be expressed as follows:

$$
\begin{aligned}
p_{1}= & a_{1} \\
p_{2}= & a_{2}+b t=a_{2}+b a_{1} \\
p_{3}= & a_{3}+b\left(a_{2}+(1+b) a_{1}\right) \\
& \ldots \\
p_{i}= & a_{i}+b\left(a_{i-1}+(1+b) a_{i-2}+\ldots+(1+b)^{i-2} a_{1}\right) \\
p_{i+1}= & a_{i+1} \\
p_{i+2}= & a_{i+2}+b t=a_{i+2}+b a_{i+1} \\
& \ldots \\
p_{n}= & a_{n}+b\left(a_{n-1}+(1+b) a_{n-2}+\ldots+(1+b)^{n-i-2} a_{i+1}\right) .
\end{aligned}
$$

By Property 1, the optimal position of common due-date $k$ is determined. Assume the maintenance activity is scheduled prior to due-date, i.e. $i<k$. The earliness cost (denoted by $Z_{j}$ ) associated with job $j, j=k, k-1, \ldots, 1$, is given by 


$$
\begin{aligned}
Z_{k}=0 \\
Z_{k-1}=\alpha p_{k} \\
Z_{k-2}=\alpha\left(p_{k}+p_{k-1}\right) \\
Z_{k-3}=\alpha\left(p_{k}+p_{k-1}+p_{k-2}\right) \\
\quad \ldots \\
Z_{i+1}=\alpha\left(p_{k}+p_{k-1}+p_{k-2}+\ldots+p_{i+2}\right) \\
Z_{i}=\alpha\left(p_{k}+p_{k-1}+p_{k-2}+\ldots+p_{i+2}+p_{i+1}+l\right) \\
Z_{i-1}=\alpha\left(p_{k}+p_{k-1}+p_{k-2}+\ldots+p_{i+2}+p_{i+1}+l+p_{i}\right) \\
\quad \ldots \\
Z_{1}=\alpha\left(p_{k}+p_{k-1}+p_{k-2}+\ldots+p_{i+2}+p_{i+1}+l+p_{i}+\ldots+p_{2}\right) .
\end{aligned}
$$

The tardiness cost (denoted by $Z_{j}$ ) associated with job $j, j=$ $k+1, \ldots, n$ is given by

$$
\begin{aligned}
& Z_{k+1}=\beta\left(p_{k+1}\right) \\
& Z_{k+2}=\beta\left(p_{k+1}+p_{k+2}\right) \\
& \ldots \\
& Z_{n}=\beta\left(p_{k+1}+p_{k+2}+\ldots+p_{n}\right)
\end{aligned}
$$

The due-date cost (denoted by $Z_{d}$ ) is given by

$$
Z_{d}=n \gamma d=n \gamma\left(p_{1}+p_{2}+\ldots+p_{i}+l+p_{i+1}+\ldots+p_{k-1}+p_{k}\right) .
$$

The total earliness, tardiness and due-date cost (for given $i<k$ ) is given by

$$
\begin{aligned}
Z= & \sum_{j=1}^{n} Z_{j}+Z_{d} \\
= & \alpha \sum_{j=1}^{k}(j-1) p_{j}+i \alpha l+\beta \sum_{j=k+1}^{n}(n-j+1) p_{j} \\
& +n \gamma\left(p_{1}+p_{2}+\ldots+p_{i}+l+p_{i+1}+\ldots+p_{k}\right) \\
= & \sum_{j=1}^{k}[n \gamma+\alpha(j-1)] p_{j}+\sum_{j=k+1}^{n}[\beta(n-j+1)] p_{j} \\
& +(n \gamma+i \alpha) l .
\end{aligned}
$$

Similarly, the total earliness, tardiness and due-date cost (for given $i \geq k$ ) is given by

$Z=\sum_{j=1}^{k}[n \gamma+\alpha(j-1)] p_{j}+\sum_{j=k+1}^{n}[\beta(n-j+1)] p_{j}+(n-i) \beta l$.

By incorporating Eq. (1) and (2), the total earliness, tardiness and due-date cost is given by

$$
Z=\sum_{j=1}^{k}[n \gamma+\alpha(j-1)] p_{j}+\sum_{j=k+1}^{n}[\beta(n-j+1)] p_{j}+M
$$

where $M=(n \gamma+i \alpha) l$ when $i<k$ or $M=(n-i) \beta l$ when $i \geq k$.

Let $w_{j}=n \gamma+\alpha(j-1)$ when $j=1,2, \ldots, k$ or $w_{j}=\beta(n-j+1)$ when $j=k+1, k+2, \ldots, n$. Then

$$
\begin{aligned}
Z= & w_{1} a_{1}+w_{2}\left(a_{2}+b a_{1}\right)+w_{3}\left(a_{3}+b a_{2}+b(1+b) a_{1}\right)+\ldots \\
& +w_{i}\left(a_{i}+b a_{i-1}+b(1+b) a_{i-2}+\ldots+b(1+b)^{i-2} a_{1}\right) \\
& +w_{i+1} a_{i+1}+w_{i+2}\left(a_{i+2}+b a_{i+1}\right) \\
& +w_{i+3}\left(a_{i+3}+b a_{i+2}+b(1+b) a_{i+1}\right)+\ldots \\
& +w_{n}\left(a_{n}+b a_{n-1}+b(1+b) a_{n-2}+\ldots+b(1+b)^{n-i-2} a_{i+1}\right)+M \\
= & W_{1} a_{1}+W_{2} a_{2}+\ldots+W_{n} a_{n}+M
\end{aligned}
$$

where

$$
\begin{aligned}
W_{1}= & w_{1}+w_{2} b+w_{3} b(1+b)+w_{4} b(1+b)^{2}+\ldots+w_{i} b(1+b)^{i-2}, \\
W_{2}= & w_{2}+w_{3} b+w_{4} b(1+b)+w_{5} b(1+b)^{2}+\ldots+w_{i} b(1+b)^{i-3}, \\
& \ldots \\
W_{i-1}= & w_{i-1}+w_{i} b \\
W_{i}= & w_{i}, \\
W_{i+1}= & w_{i+1}+w_{i+2} b+w_{i+3} b(1+b)+w_{i+4} b(1+b)^{2}+\ldots \\
& \quad+w_{n} b(1+b)^{n-i-2}, \\
W_{i+2}= & w_{i+2}+w_{i+3} b+w_{i+4} b(1+b)+w_{i+5} b(1+b)^{2}+\ldots \\
& +w_{n} b(1+b)^{n-i-3}, \\
& \quad \ldots \\
W_{n-1}= & w_{n-1}+w_{n} b, \text { and } \\
W_{n}= & w_{n} .
\end{aligned}
$$

Once the position of maintenance activity has been determined, by the Property 2 and the sorting technique, Eq. (4) can be solved in $O(n \log n)$ time. Since the maintenance activity can be scheduled after any one of the jobs, $n$ different positions must be solved to guarantee a global optimal solution. We conclude the following theorem holds.

Theorem 1. The $1\left|a c, p_{i}=a_{i}+b t\right| \sum_{i}\left(\alpha E_{i}+\beta T_{i}+\gamma d\right)$ problem can be solved in $O\left(n^{2} \log n\right)$ time.

\section{CONCLUSION}

This study considers an optional maintenance activity scheduling and due-date assignment under linear deteriorating jobs simultaneously. We show that the problem can be solved in polynomial time. 
Future research may focus on a similar problem with maintenance activity over and over throughout the planing horizon. It would also be interesting to investigate an extension of this problem to a general form of due-date (due-window).

\section{REFERENCES}

1. Alidaee, B. and Womer, N. K., "Scheduling with time dependent processing times: review and extensions," Journal of the Operational Research Society, Vol. 50, pp. 711-720 (1999).

2. Baker, K. R. and Scudder, G. D., "Sequencing with earliness and tardiness penalties: a review," Operations Research, Vol. 38, pp. 22-35 (1990).

3. Browne, S. and Yechiali, U., "Scheduling deteriorating jobs on a single processor," Operations Research, Vol. 38, pp. 495-498 (1990).

4. Chang, P. C., Chen, S. H., and Mani, V., "A note on due-date assignment and single machine scheduling with a learning/aging effect," International Journal of Production Economics, Vol. 117, pp. 142-149 (2009).

5. Cheng, T. C. E., Ding, Q., and Lin, B. M. T., "A concise survey of scheduling with time-dependent processing times," European Journal of Operations Research, Vol. 152, pp. 1-13 (2004).

6. Cheng, T. C. E., Kang, L., and Ng, C. T., "Due-date assignment and single machine scheduling with deteriorating jobs," Journal of the Operational Research Society, Vol. 55, pp. 198-203 (2004).

7. Gordon, V. S., Proth, J. M., and Chu, C., "A survey of the state-of-art of common due date assignment and scheduling research," European Journal of Operational Research, Vol. 139, pp. 1-25 (2002).

8. Gordon, V. S. and Tarasevich, A. A., "A note: Common due date assignment for a single machine scheduling with the rate-modifying activity," Computers \& Operations Research, Vol. 36, pp. 325-328 (2009).
9. Graham, R. L., Lawler, E. L., Lenstra, J. K., and Rinnooy Kan, A. H. G., "Optimization and approximation in deterministic sequencing and scheduleing: A survey," Annals of Discrete Mathematics, Vol. 5, pp. 287-326 (1979).

10. Hardy, G. H., Littlewood, J. E., and Polya, G., Inequalities, Cambridge University Press, London (1967).

11. Kunnathur, A. S. and Gupta, S. K., "Minimizing the makespan with late start penalties added to processing times in a single facility scheduling problem," European Journal of Operations Research, Vol. 47, pp. 56-64 (1990).

12. Kuo, W. H. and Yang, D. L., "A note on due-date assignment and single-machine scheduling with deteriorating jobs," Journal of the Operational Research Society, Vol. 59, pp. 857-859 (2008).

13. Ma, Y., Chu, C., and Zuo, C., "A survey of scheduling with deterministic machine availability constraints," Computers \& Industrial Engineering, Vol. 58, pp. 199-211 (2010).

14. Mosheiov, G., "Scheduling jobs with step-deterioration: Minimizing makespan on single and multi-machine," Computers and Industrial Engineering, Vol. 28, pp. 869-879 (1995).

15. Mosheiov, G., "V-shaped policies to schedule deteriorating jobs," Journal of the Operational Research Society, Vol. 47, pp. 1184-1191 (1996).

16. Mosheiov, G. and Oron, D., "Due-date assignment and maintenance activity scheduling problem," Mathematical and Computer Modelling, Vol. 44, pp. 1053-1057 (2007).

17. Panwalkar, S. S., Smith, M. L., and Seidmann, A., "Common due date assignment to minimize total penalty for the one machine scheduling problem," Operations Research, Vol. 30, pp. 391-399 (1982).

18. Wang, H., "A survey of maintenance policies of deterioration systems," European Journal of Operational Research, Vol. 139, pp. 469-489 (2008). 